\title{
Improved Oil Recovery in Fluvial Dominated Deltaic Reservoirs of Kansas - Near-Term
}

\author{
Quarterly Report \\ April 1 - June 30, 1998
}

\author{
By: \\ D. W. Green; G. P. Willhite; A. Walton; D. McCune \\ R. Reynolds; M. Michnick; L. Watney
}

\author{
Work Performed Under Contract No.: DE-FC22-93BC14957 \\ For \\ U.S. Department of Energy \\ Office of Fossil Energy \\ Federal Energy Technology Center \\ P.O. Box 880 \\ Morgantown, West Virginia 26507-0880
}

By

The University of Kansas Center for Research, Inc.

Lawrence, Kansas 66045 


\section{Disclaimer}

This report was prepared as an account of work sponsored by an agency of the United States Government. Neither the United States Government nor any agency thereof, nor any of their employees, makes any warranty, express or implied, or assumes any legal liability or responsibility for the accuracy, completeness, or usefulness of any information, apparatus, product, or process disclosed, or represents that its use would not infringe privately owned rights. Reference herein to any specific commercial product, process, or service by trade

name, trademark, manufacturer, or otherwise does not necessarily constitute or imply its endorsement, recommendation, or favoring by the United States Government or any agency thereof. The views and opinions of authors expressed herein do not necessarily state or reflect those of the United States Government or any agency thereof. 
Cooperative A greement N umber DE-FC22-93BC 14957--23

The U niversity of Kansas Center for Research, Inc.

July 15, 1998

Budget Period \#1 Duration from 06/18/93 - 03/31/95

Budget Period \#2 Duration from 04/01/95 - 12/31/98

DOE A ward \$2,007,446

\author{
Program M anager \\ D on W. Green \\ University of Kansas \\ Lawrence, Kansas \\ Principal Investigators \\ D on W. Green \\ G. Paul Willhite
}

Co-Investigators

A. Walton, D. M cCune, R. Reynolds, M. M ichnick, L. Watney

DOE Project Officer

$R$ honda P. L indsey

Bartlesville Project Office

Reporting Period 04/01/98 - 06/30/98

(20th Quarterly Report)

"U.S./DOE PATENT CLEARANCE IS NOT REQUIRED
PRIOR TO PUBLICATION OF THIS DOCUMENT" 


\section{O bjectives}

The objective of this project is to address waterflood problems of the type found in Morrow sandstone reservoirs in southwestern K ansas and in Cherokee Group reservoirs in southeastern Kansas. Two demonstration sites operated by different independent oil operators are involved in this project. The Stewart Field is located in Finney County, Kansas and is operated by PetroSantander, Inc. The Nelson Lease is located in Allen County, Kansas, in the N.E. Savonburg Field and is operated by James E. Russell Petroleum, Inc.

General topics to be addressed are 1) reservoir management and performance evaluation, 2) waterflood optimization, and 3) the demonstration of recovery processes involving off-the-shelf technologies which can be used to enhance waterflood recovery, increase reserves, and reduce the abandonment rate of these reservoir types.

In the Stewart Project, the reservoir management portion of the project conducted during Budget Period 1 involved performance evaluation. This included 1) reservoir characterization and the development of a reservoir database, 2) volumetric analysis to evaluate production performance, 3) reservoir modeling, 4) laboratory work, 5) identification of operational problems, 6) identification of unrecovered mobile oil and estimation of recovery factors, and 7) identification of the most efficient and economical recovery process.

To accomplish these objectives the initial budget period was subdivided into three major tasks. The tasks were 1) geological and engineering analysis, 2) laboratory testing, and 3) unitization. Due to the presence of different operators within the field, it was necessary to unitize the field in order to demonstrate a field-wide improved recovery process. This work was completed and the project moved into Budget Period 2.

Budget Period 2 objectives consisted of the design, construction, and operation of a field-wide waterflood utilizing state-of-the-art, off-the-shelf technologies in an attempt to optimize secondary oil recovery. To accomplish these objectives the second budget period was subdivided into five major tasks. The tasks were 1) design and construction of a waterflood plant, 2) design and construction of a water injection system, 3) design and construction of tank battery consolidation and gathering system, 4) initiation of waterflood operations and reservoir management, and 5) technology transfer. Tasks 1-3 have been completed and water injection began in October 1995.

In the Savonburg Project, the reservoir management portion involves performance evaluation. This work included 1) reservoir characterization and the development of a reservoir database, 2) identification of operational problems, 3) identification of near wellbore problems such as plugging caused from poor water quality, 4) identification of unrecovered mobile oil and estimation of recovery factors, and 5) preliminary identification of the most efficient and economical recovery process i.e., polymer augmented waterflooding or infill drilling (vertical or horizontal wells).

To accomplish this work the initial budget period was subdivided into four major tasks. The tasks included 1) geological and engineering analysis, 2) waterplant optimization, 3) wellbore cleanup and pattern changes, and 4) field operations. This work was completed and the project has moved into Budget Period 2.

The Budget Period 2 objectives consisted of continual optimization of this mature waterflood in an attempt to optimize secondary and tertiary oil recovery. To accomplish these objectives the second budget period is subdivided into six major tasks. The tasks were 1) waterplant development, 2) profile modification treatments, 3) pattern changes, new wells and wellbore cleanups, 4) reservoir development (polymer flooding), 5) field operations, and 6) technology transfer. 


\section{Summary of Technical Progress}

\section{Stewart Field Project}

\section{Task II.1 - Design/C onstruct W aterflood Plant}

Summary of work in last quarter

Completed installation of the horizontal injection pump in A pril. M aintained injection rates of approximately 10,250 BWPD during this quarter. Continued evaluating other water sources for less corrosive injection water.

Summary of planned work for next quarter

Will test additional water supply zones/sources in Sherman \#5.

\section{Task II.2 - Design/C onstruct Injection System}

Summary of work in last quarter

None.

Summary of planned work for next quarter

None planned.

\section{Task II.3 - Design/C onstruct Battery C onsolidation and Gathering System}

Summary of work in last quarter

None.

Summary of planned work for next quarter

None planned.

\section{Task II.4 - Waterflood Operations and Reservoir M anagement}

Summary of work in last quarter

A pressure build-up test was previously performed on the Mackey No. 1 that indicated positive skin damage. This well was hydraulically fractured in an attempt to remove the excessive skin damage. The treatment was unsuccessful in increasing production.

Ongoing pump changes and speeding up pumping units were performed during the quarter on several wells. These changes are made as a result of the well testing program that identifies wells with production problems, rising fluid levels, abnormal production trends and low pump efficiencies. The changes that were made are a continued effort to maximize oil production and keep all the wells near a 
pumped off condition. Also four new progressive gravity pumps were installed on producing wells to increase fluid production.

The M ackey N o. 3 was re-entered in an attempt to return this TA'd well to production. This work was unsuccessful.

The computer model developed at the Tertiary Oil Recovery Project at the University of Kansas was revised to history match waterflood production and injection. The availability of waterflood data necessitated these modifications to the model. The basic structure of the model, the four layers, was retained but changes in the petrophysical (skin, $x$ and $y$ permeability) properties were made to get a reasonable match in the oil and water production peaks and the arrival of the waterflood front. The fluid levels were maintained equal to the reservoir reported data and well production was predicted accordingly, i.e. the simulation was performed under bottom hole pressure as the limiting constraint.

To arrive at a reasonable value for the gas-oil ratio, a series of runs were performed by changing gas-oil ratios and the flood front arrivals were compared with the actual water front arrival in the field. The original ratio of $37 \mathrm{SCF} / \mathrm{STB}$ turned out to be the most reasonable value. A revised set of relative permeability data regressed from the old relative permeability data were used. Also, the relative permeability data were further adjusted to reduce water production and the early arrival of the water response to the flood. The vertical permeability of the fourth layer was adjusted to study the effect of the pressure support of the fourth layer on water and oil production and on the arrival of the flood response. It was found that a vertical permeability factor of $0.005(0.5 \%)$ of the original core value gave adequate pressure support. Different simulation runs were performed by varying the permeability of the top three layers and observing its effect on the match. It was observed that permeability values of $67.5 \%$ of the original core permeability values produced a reasonable match. This is acceptable and justified because the original core values were measured with respect to air, and a factor of 0.7 is generally used to get the permeability with respect to liquid phase.

To history match fluid production of individual wells, the skin values of each well were modified. The skin only modifies the permeability of the well grid block. In cases where the maximum negative skin was reached (the negative maximum skin is a function of the grid block size) local modifications to the permeability were made to get better history matches. The local modifications typically extended to a 3 X 3 grid, and in some instances to a $5 \times 5$ grid, with the well located at the center. These modifications were applied to all the layers and were done at the time of completion and when hydraulic fracturing occurred, if needed.

A few wells had their flood front arriving later or earlier than observed in the field. To correct this, the grid permeability between the injector and the producing wells was altered. The altered path was as narrow and direct as possible. These modifications were applied to individual layers as needed. A few wells showed both oil and water responses to the flood when there was none observed in the field. These wells were generally directly above or near the region in communication with the underlying Ste. Genevieve and St. Louis formations (the fourth layer in this model). The communication between the third and fourth layer near these wells was removed by closing the vertical permeability (i.e., $K_{z}=0$ ). In other instances, some wells did not show a response or the water response to the flood was not large enough. These wells had some surrounding grid blocks opened to the fourth layer to allow additional water influx. The grid blocks altered were usually a 5 X 5 grid with the well located at the center. A few wells had two to three distinct oil spike responses to the flood indicating that different layers had broken through at different times. These wells were modeled by altering the path permeability, as needed, of the individual layers. 
The revised history match for the field is shown in Figure 1. There are three distinct peaks in oil production. The first is due to the field-wide development, the second due to the hydraulic fracturing of the field and the third peak is the response to the waterflood. The data points indicate actual production figures while the solid lines indicate the simulated values. The recent decline in actual oil production is due to excessive downtime due to workovers to upsize pumping equipment, rod parts, pump changes, water supply well downtime and work on the injection system. This temporarily effected the normal trend in production, which has since stabilized and is following the trend predicted by the simulation. Oil production rates, cumulative oil, and water production rates are presented in red, green, and blue, respectively. Field wide oil, water, and gas cumulative productions are reported in Table 1. There are three regimes of production. The first is the primary production match, the second is the matching of the waterflood period to date and the third is the prediction of the field performance through the year 2010.

\begin{tabular}{|c|c|c|c|c|c|c|}
\hline & $\begin{array}{r}\text { Primar } \\
\text { thro }\end{array}$ & $\begin{array}{l}\text { roduction } \\
9 / 1995\end{array}$ & Produc & $\begin{array}{l}\text { through } \\
98\end{array}$ & $\begin{array}{r}\text { Produc } \\
1\end{array}$ & $\begin{array}{l}\text { n through } \\
010\end{array}$ \\
\hline & Actual & Simulated & Actual & Simulated & A ctual & Simulated \\
\hline Cumulative Oil (M STB) & 3.593 & 3.776 & 4.62 & 4.645 & $\mathrm{~N} / \mathrm{A}$ & 8.872 \\
\hline Cumulative Water (M M STB) & 1.348 & 1.186 & 2.51 & 2.026 & $\mathrm{~N} / \mathrm{A}$ & 38.06 \\
\hline Cumulative Gas (M M SCF) & $\mathrm{N} / \mathrm{A}$ & 814 & $\mathrm{~N} / \mathrm{A}$ & 841 & $N / A$ & 848 \\
\hline Pressure Drop (psi) & $\sim 1000$ & & $\mathrm{~N} / \mathrm{A}$ & & $\mathrm{N} / \mathrm{A}$ & \\
\hline
\end{tabular}

The prediction indicates additional production of approximately 4 million barrels of oil. Figure 2 illustrates the oil saturation distribution of the field as of June 1998. The three layers are separated from each other to provide better visualization. The color scale can be seen at the bottom. The first layer clearly indicates the presence of large areas of unswept oil that should be considered for further exploitation. These regions are represented in blue.

A meeting between PetroSantander and University personnel was conducted in May 1998 to discuss the model behavior and the prediction. PetroSantander presented two locations that they suspected had potential for oil production. These sites corresponded with the regions that had unswept oil on the simulated oil saturation distribution. This provided additional support to the accuracy of the model. Two simulated wells were drilled in these areas and their combined output was estimated to be 300,000 barrels from October 1, 1998 through the year 2010. A few additional runs were performed by drilling new wells at other sites that the model indicated had potential. The model predicted economic wells could be drilled at these locations.

Continued to monitor production and injection rates, water supply volumes, and injection pressures. Continued the ongoing testing of producing wells with test trailers and fluid level instruments. Ongoing allocation of the injection volumes in the injection wells were performed based on response in producers and injectors. Cumulative water injection through J une is $6,070,071 \mathrm{bbls}$. Oil production has continued to increase and as of July 1, 1998 total incremental waterflood response is approximately 2000 BOPD. Total field production is approximately 2260 BOPD and 3310 BWPD. Total incremental waterflood production through June 1998 is 1,145,644 BO. Figure 3 is a plot showing average daily totals for injection and production data by month for the field since the initiation of the waterflood. 
Summary of planned work for next quarter

Continue to monitor for response at producing wells with well tests and fluid levels. U pdate the reservoir computer model and simulate when applicable. Upgrade pumping equipment as necessary. Several increasing fluid levels will be addressed with larger pumping equipment and evaluation of additional progressive cavity pumps will be conducted.

Evaluation of three infill drilling locations will be conducted. These locations include south of the Pauls 9-1, southwest of the M eyer 10-4, and replacement well for the Sherman N 0. 5.

\section{Task II.5 - Technology Transfer}

Summary of work in last quarter

1. A presentation on the Stewart Field waterflood was presented to the Tertiary Oil Recovery Project's advisory board on A pril 7, 1998 in Wichita, KS.

2. Information pertaining to the Stewart Field waterflood was displayed on the exhibition booth for the Tertiary Oil Recovery Project at a workshop titled, "Horizontal Drilling Applications in Kansas", sponsored by the North Midcontinent Regional Lead Organization of the Petroleum Technology Transfer Council on June 16, 1998 in Wichita, KS. A brochure containing detailed information on the Stewart Field waterflood was developed, printed and distributed at the workshop.

3. Continued to publicize information on the success of the Stewart Field waterflood. Operators throughout the region continue to visit the field to view the state-of-the-art waterflood installation and computerized monitoring system.

Summary of planned work for next quarter

Continue to publicize information on the success of the Stewart Field waterflood. 
Field Oil and Water Production

Stewart Field, TORP Simulation

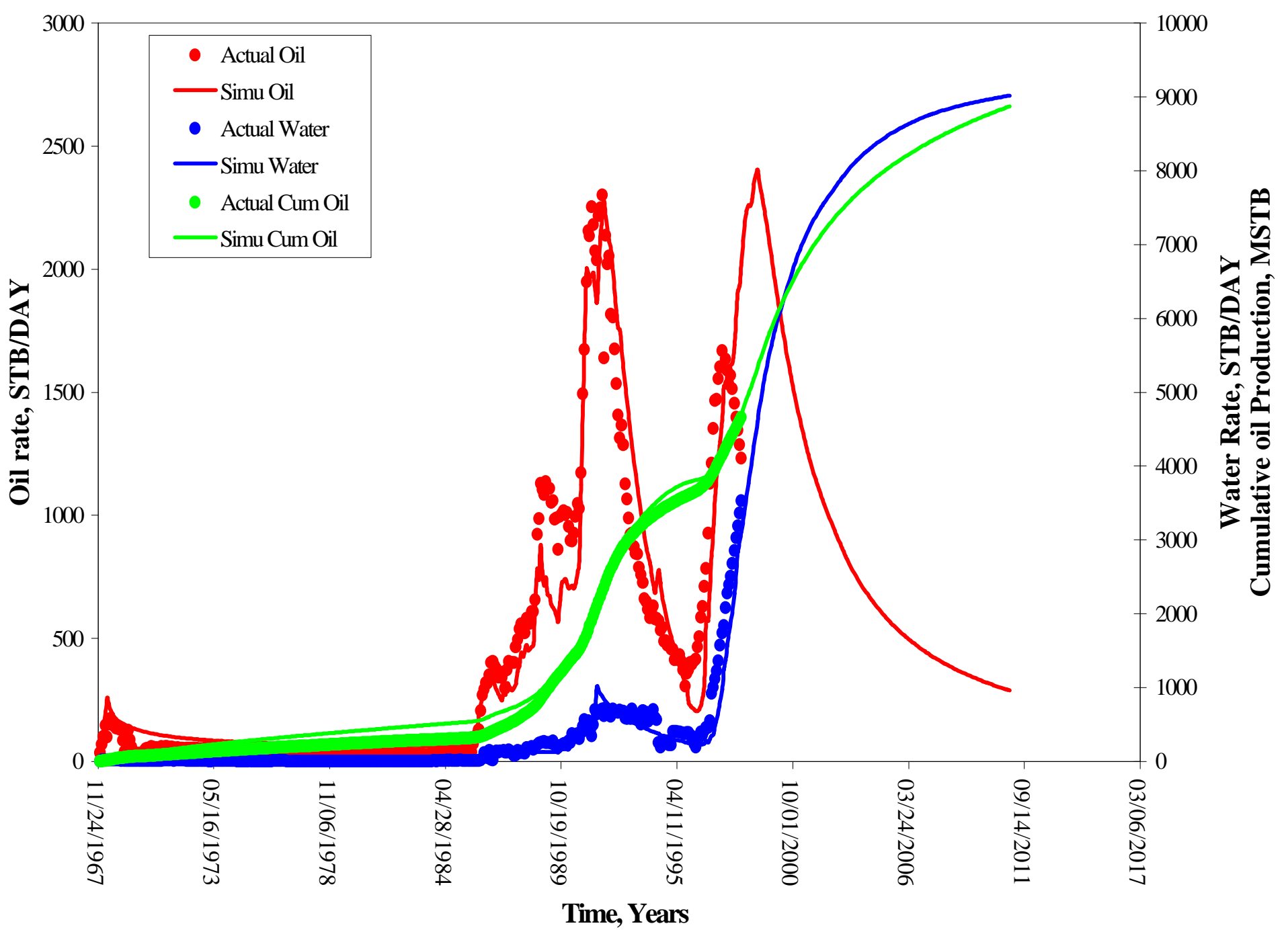

Figure 1. Stewart Field Actual versus Simulated Production. 


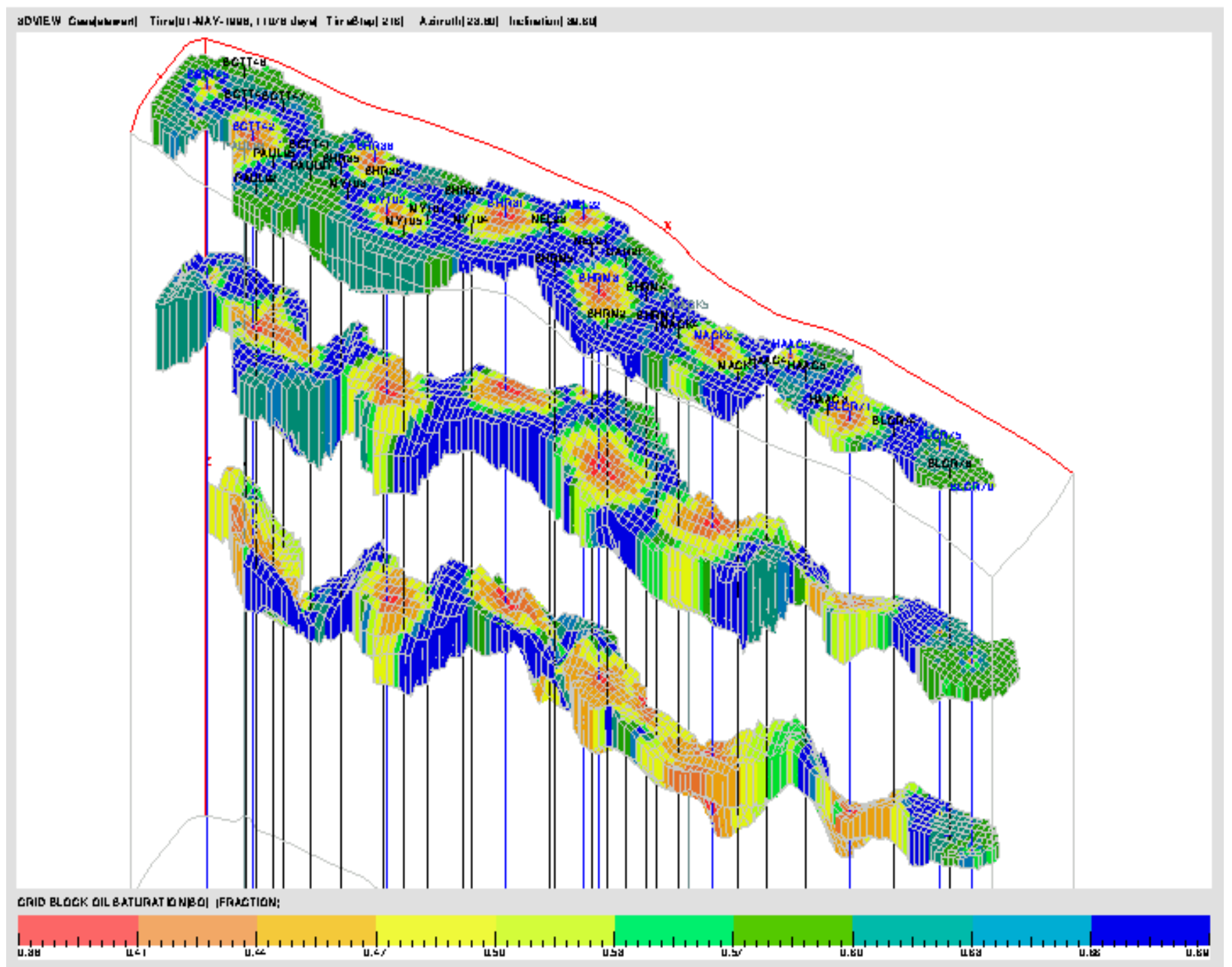

Figure 2. Stewart Field Simulated O il Saturation Distribution as of J une 1998. 


\section{Stewart Waterflood Average Daily Totals}

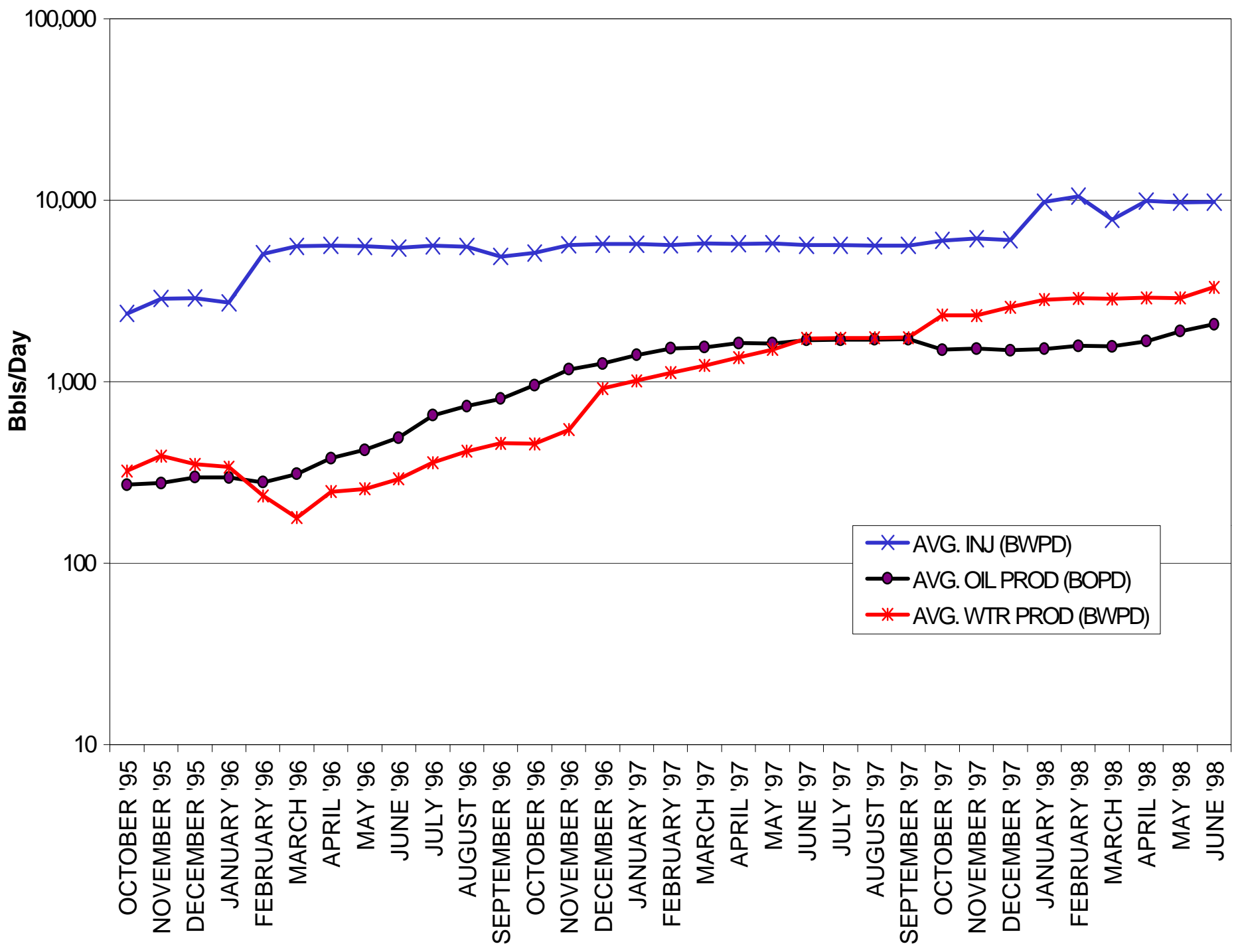

Figure 3. Stewart Field injection and Production Data since Initiation of the W aterflood. 


\section{Summary of Technical Progress}

\section{Savonburg Field Project}

\section{Task II.1 - Water Plant Development}

Summary of work in last quarter

Testing of the AFU system continues. A new centrifugal pump was installed M ay 5 and with the addition of new venturis and larger piping the performance of the system has improved. Bench filtration tests are performed weekly.

Summary of work planned for next quarter

The water treatment program will continue until all scenarios have had a sufficient time to be tested. A hydroclone will be added for solids removal.

\section{Task II.2 - Profile M odification Treatments}

Summary of work in last quarter

No channelblock treatments were performed during this quarter.

Temperature surveys were performed on wells RW-1 (3 times), RW-6 and RW-8. M echanical integrity tests were performed on wells RW-9, RW-12, RW-13, RW-16, RW-18, KW-9, HW-18 and HW -23 . tubing.

The B3 zone was isolated for injection in wells HW-18 and RW-8 by utilizing a packer on

Summary of work planned for next quarter

Wells will be tested, cleaned and worked as needed.

\section{Task II.3 - Pattern Changes and Wellbore Cleanup}

Summary of work in last quarter

The following wells were serviced during the last quarter; $\mathrm{H}-10, \mathrm{H}-16$ (twice, replaced 1"), H-21 (twice), H-22 (three times), H-26 (three times), H-30 (replaced 1"), H-20, K-54 (twice), H3 (twice) and 0-1 (replaced 1").

Summary of planned work for next quarter

W ells will be tested, cleaned and worked on as needed.

\section{Task II.4 - Reservoir Development (Polymer Flooding)}


Summary of work in last quarter

Waiting on a decision to implement polymer flooding.

Summary of work for next quarter

Waiting on a decision to implement polymer flooding.

\section{Task II.5 - Field Operations}

Summary of work in last quarter

Normal field operations have included: 1) monitoring wells on a daily basis, 2) repairing waterplant, piping, and wells as required, 3) collecting daily rate and pressure data, and 4) solving any other daily field operational problem that might occur.

\begin{tabular}{|c|c|}
\hline Month & Oil Production \\
\hline October 1993 & $26.4 \mathrm{~B} / \mathrm{D}$ \\
\hline November 1993 & $30.7 \mathrm{~B} / \mathrm{L}$ \\
\hline December 1993 & $32.0 \mathrm{~B} / \mathrm{D}$ \\
\hline January 1994 & $30.8 \mathrm{~B} / \mathrm{D}$ \\
\hline February 1994 & $30.9 \mathrm{~B} / \mathrm{D}$ \\
\hline M arch 1994 & $30.3 \mathrm{~B} / \mathrm{D}$ \\
\hline A pril 1994 & $29.1 \mathrm{~B} / \mathrm{D}$ \\
\hline May 1994 & $28.5 \mathrm{~B} / \mathrm{D}$ \\
\hline J une 1994 & $30.3 \mathrm{~B} / \mathrm{D}$ \\
\hline July 1994 & $28.9 \mathrm{~B} / \mathrm{D}$ \\
\hline A ugust 1994 & $24.6 \mathrm{~B} / \mathrm{D}$ \\
\hline October 1994 & $23.0 \mathrm{~B} / \mathrm{D}$ \\
\hline November 1994 & $25.7 \mathrm{~B} / \mathrm{D}$ \\
\hline December 1994 & $27.8 \mathrm{~B} / \mathrm{D}$ \\
\hline J anuary 1995 & $27.0 \mathrm{~B} / \mathrm{D}$ \\
\hline February 1995 & $25.3 \mathrm{~B} / \mathrm{D}$ \\
\hline M arch 1995 & $22.4 \mathrm{~B} / \mathrm{D}$ \\
\hline A pril 1995 & $22.4 \mathrm{~B} / \mathrm{D}$ \\
\hline M ay 1995 & $25.0 \mathrm{~B} / \mathrm{D}$ \\
\hline J une 1995 & $23.9 \mathrm{~B} / \mathrm{D}$ \\
\hline July 1995 & $26.8 \mathrm{~B} / \mathrm{D}$ \\
\hline A ugust 1995 & $25.2 \mathrm{~B} / \mathrm{D}$ \\
\hline September 1995 & $24.8 \mathrm{~B} / \mathrm{D}$ \\
\hline October 1995 & $24.4 \mathrm{~B} / \mathrm{D}$ \\
\hline N ovember 1995 & $24.4 B / D$ \\
\hline December 1995 & $26.3 \mathrm{~B} / \mathrm{D}$ \\
\hline January 1996 & $28.0 \mathrm{~B} / \mathrm{D}$ \\
\hline February 1996 & $29.2 \mathrm{~B} / \mathrm{D}$ \\
\hline M arch 1996 & $27.2 \mathrm{~B} / \mathrm{D}$ \\
\hline April 1996 & $26.7 \mathrm{~B} / \mathrm{D}$ \\
\hline M ay 1996 & $26.6 \mathrm{~B} / \mathrm{D}$ \\
\hline
\end{tabular}




\begin{tabular}{|c|c|}
\hline J une 1996 & $24.9 \mathrm{~B} / \mathrm{D}$ \\
\hline July 1996 & $25.4 \mathrm{~B} / \mathrm{D}$ \\
\hline A ugust 1996 & $26.5 \mathrm{~B} / \mathrm{D}$ \\
\hline September 1996 & $26.1 \mathrm{~B} / \mathrm{D}$ \\
\hline October 1996 & $27.1 \mathrm{~B} / \mathrm{D}$ \\
\hline N ovember 1996 & 26.4 B/D \\
\hline D ecember 1996 & $27.8 \mathrm{~B} / \mathrm{D}$ \\
\hline January 1997 & $26.9 \mathrm{~B} / \mathrm{D}$ \\
\hline F ebruary 1997 & $26.9 \mathrm{~B} / \mathrm{D}$ \\
\hline M arch 1997 & $27.5 \mathrm{~B} / \mathrm{D}$ \\
\hline A pril 1997 & $26.3 \mathrm{~B} / \mathrm{D}$ \\
\hline M ay 1997 & $25.5 \mathrm{~B} / \mathrm{D}$ \\
\hline J une 1997 & $24.6 \mathrm{~B} / \mathrm{D}$ \\
\hline July 1997 & $23.5 \mathrm{~B} / \mathrm{D}$ \\
\hline A ugust 1997 & $24.3 \mathrm{~B} / \mathrm{D}$ \\
\hline September 1997 & $23.8 \mathrm{~B} / \mathrm{D}$ \\
\hline October 1997 & $22.9 \mathrm{~B} / \mathrm{D}$ \\
\hline N ovember 1997 & $23.5 \mathrm{~B} / \mathrm{D}$ \\
\hline December 1997 & $21.7 \mathrm{~B} / \mathrm{D}$ \\
\hline J anuary 1998 & $19.0 \mathrm{~B} / \mathrm{D}$ \\
\hline F ebruary 1998 & $18.3 \mathrm{~B} / \mathrm{D}$ \\
\hline M arch 1998 & $18.9 \mathrm{~B} / \mathrm{D}$ \\
\hline A pril 1998 & $18.0 \mathrm{~B} / \mathrm{D}$ \\
\hline M ay 1998 & $19.5 \mathrm{~B} / \mathrm{D}$ \\
\hline J une 1998 & $18.8 \mathrm{~B} / \mathrm{D}$ \\
\hline
\end{tabular}

Field operations will be continued.

\section{Task II.6 - Technology Transfer}

Summary of work in last quarter

M onthly meetings were conducted with personnel from the James Russell Petroleum, Inc., the Tertiary Oil Recovery Project and the Petroleum Technology Transfer Council attending.

Summary of planned work for next quarter

The field will be visited by other operators from the area. 